\title{
INVESTIGATIONS ON THE DISTRIBUTION OF \\ SCHISTOSOMA TURKESTANICUM SKRJABIN, 1913 \\ (TREMATODA: SCHISTOSOMATIDAE) INFECTION OF \\ RED DEER IN HUNGARY AND A COMBINED METHOD FOR THE DETECTION OF S. TURKESTANICUM EGGS IN DROPPINGS
}

\author{
Alexandra JUHÁSZ and Gábor MAJOROS* \\ Department of Parasitology and Zoology, University of Veterinary Medicine, István u. 2, \\ H-1078 Budapest, Hungary
}

(Received 23 March 2018; accepted 25 July 2018)

\begin{abstract}
Additional geographical distribution of the Central European populations of Schistosoma turkestanicum and the detectability of their eggs in droppings were investigated in red deer samples, because this rare species had previously been shown only in a single Hungarian habitat. Samples from visceral organs, intestinal contents, and droppings on the ground from 11 hunting areas of Hungary were investigated to find a new presence of this fluke. Close to the first site of detection in the Gemenc forest another habitat along the southern border of the country was found where the parasite lives in red deer. Therefore, it is possible that the worm also occurs in neighbouring Serbia or Croatia. Schistosoma turkestanicum causes a low-intensity infection in red deer and this host sheds low amounts of eggs, therefore the eggs are difficult to detect. Droppings were cleared by sedimentation, filtered by sieve screening and then the eggs were flotated using solutions with an increasing density of $1200 \mathrm{~g} / \mathrm{L}, 1300 \mathrm{~g} / \mathrm{L}, 1350 \mathrm{~g} / \mathrm{L}$, and $1400 \mathrm{~g} / \mathrm{L}$ while they were being stained red with acid fuchsin. Eggs in fresh faeces can be most efficiently separated from plant fibres using a flotation solution of $1350 \mathrm{~g} / \mathrm{L}$ density, but in some cases eggs in old dung can be detected using a solution of a specific gravity lower or higher than that. By combining the advantages of the three concentration processes, eggs of $S$. turkestanicum, which are more recognisable by the red stain, can be found in samples in which they are present at a density lower than $1 / \mathrm{g}$.
\end{abstract}

Key words: Schistosoma turkestanicum, Schistosoma egg, red deer, faecal parasite, flotation technique

Several species of tropical blood flukes within the genus Schistosoma cause schistosomiasis (or, according to a proposal from the World Association

*Corresponding author; E-mail: majoros.gabor@univet.hu; Phone: 0036 (1) 478-4275

Open Access. This is an open-access article distributed under the terms of the Creative Commons AttributionNonCommercial 4.0 International License (https://creativecommons.org/licenses/by-nc/4.0/), which permits unrestricted use, distribution, and reproduction in any medium for non-commercial purposes, provided the original author and source are credited, a link to the CC License is provided, and changes - if any - are indicated. 
for the Advancement of Veterinary Parasitology, more correctly schistosomosis; Kassai et al., 1988), a long-term chronic illness affecting humans, livestock and wildlife (Malek, 1980; Manson-Bahr and Bell, 1987; De Bont and Vercruysse, 1998; Utzinger et al., 2009; Agrawal, 2012). Some Schistosoma species infecting animals are zoonotic (Malek, 1980; Rudge et al., 2008); therefore, studying animal schistosomiasis can improve understanding of the process of human infections and give insights into their prevention. Recently, Schistosoma turkestanicum Skrjabin, 1913, which lives mainly in ruminants, has become of particular interest in Asia and Europe (Wang et al., 2009; Juhász et al., 2016; Liu et al., 2016). To date, studies of infections causing schistosomiasis in animals have focused on domestic cattle, sheep and goats (Massoud, 1971; Maleki et al., 1994). Although to date no accounts of human schistosomiasis being caused by $S$. turkestanicum have been recorded, the parasite is closely related to human blood flukes and its larvae released from lymnaeid water snails may cause cercarial dermatitis (CD) in humans (Wang et al., 2009; Aldhoun and Littlewood, 2012). The condition of $\mathrm{CD}$ is caused by the penetration of non-specific cercariae resulting in an acute allergic reaction, presenting in maculo-papulo-vesicular eruptions followed by intense itching, fever and a swelling of lymph nodes (Malek, 1980). In some cases of $\mathrm{CD}$ there have been reports of anaphylactic shock due to continued exposure, and some experimental evidence suggests that there may also be pathology beyond the skin with some agents of $\mathrm{CD}$ being able to affect the lungs and also cause neurological problems (Kolarova, 2007). In many countries of Asia CD caused by $S$. turkestanicum is considered to be an emerging public health problem especially for people who work in water-covered lands, therefore it is paramount to be able to monitor potential host animals to identify them as reservoirs of S. turkestanicum (Lien et al., 1975; Liu et al., 1976; Sahba and Malek, 1979; Farahnak and Essalat, 2003). Cercarial dermatitis caused by the larvae of S. turkestanicum was detected in Hungary (Juhász et al., 2016) but we do not know about any autochthonous human schistosomiasis in Hungary.

While the difficulties of diagnosing human schistosomiasis in most cases can be solved through the combination of multiple test procedures or repetition of patient examination (Chaia et al., 1968), blood fluke infections of live animals, especially wild animals living in their natural habitat, are more difficult to detect. For this reason, Schistosoma infection of mammals is often revealed in animals which are slaughtered at abattoirs (Agrawal and Alwar, 1992; De Bont and Vercruysse, 1998; Makundi et al., 1998), eviscerated by hunters (Zakhryalov, 1978 ) or through the examination of animal carcasses (Witenberg and Lengy, 1966; Arfaa et al., 1995). This is usually the case with studies to detect $S$. turkestanicum infection (Massoud, 1971, 1973). However, in order to detect the presence of blood flukes in wild animals it is generally accepted to test droppings for the presence of parasite eggs (Pitchford, 1976; Pitchford and Visser, 1981; Brant et al., 2013; Červená et al., 2016), as animals cannot be sacrificed for the sake of 
parasitological testing alone. In most cases, testing of the carcass of shot game is also difficult because it cannot be obtained outside the hunting season, and the internal organs are processed or destroyed promptly after hunting. In contrast, theoretically the droppings of infected game always contain some parasite eggs, so infection of the animal can be detected by testing such faecal samples.

Infection of red deer in Hungary with $S$. turkestanicum has been known since 2002 (Majoros et al., 2010). This fluke of Asian origin was found only in the southern part of the country, in the Gemenc forests which is a floodplain along the river Danube. Despite the fact that $S$. turkestanicum occurs in the central part of Asia in several domestic animals and several wild animal species (Skrjabin, 1951), in Hungary it has only been found in red deer. In Asia there are no reliable data on the infection of that host by this parasite although other deer species were mentioned as definitive hosts for the worm (Skrjabin, 1951; Azimov, 1971; Zakhryalov, 1978). This is probably the only native mammalian blood fluke in Europe (Lawton and Majoros, 2013); however, its distribution beyond the forest of Gemenc and across the continent remains unknown. In order to investigate the area of distribution of $S$. turkestanicum in Hungary, we investigated wild game in several hunting areas for the purpose of establishing the presence or absence of the parasite. We endeavoured to identify worms and their eggs in the internal organs of shot deer and in their droppings found in woods. Offal can only be obtained during the hunting season (September-January) but it is possible to collect faecal samples from the ground all year round. Both types of samples were used together to detect the occurrence of $S$. turkestanicum.

In some cases only a few small pieces of organs could be used for examination, which do not provide detailed information on the worm burden (i.e. the intensity of infection) in the infected animals. Therefore, our focus was primarily on the coprology tests of the droppings of game, which allowed us to determine the occurrence of $S$. turkestanicum eggs in those samples and to detect the infection in certain deer stocks.

Usually the density of eggs found was lower than $1 \mathrm{egg} / 10$ grams of fresh faeces (unpublished observation). To find a very small amount of detectable eggs in droppings, a really effective concentration procedure should be used. Here we present a method that combines the benefits of filtration, sedimentation and flotation procedures to make it easier to find $S$. turkestanicum eggs.

\section{Materials and methods}

\section{Origin of the samples}

Faecal samples of deer (and some from wild boars) were collected or obtained from professional hunters at 11 different hunting sites across Hungary (Table 1 and Fig. 1). In seven hunting areas (Gemenc, Karapancsa, Szekszárd 
Hills, Zselic, Bakony, Szigetköz, Nyírség) we were also able to examine internal organs of hunted game, while in four places (Kis-Balaton, Pilis, Mátra, Bükk) we could only carry out tests on the droppings. Every sample was derived from forested and marshland habitats where deer could wad into water or wallow in mud. The investigations took place between 2010 and 2017, at irregular intervals. All the samples of organs were collected from the carcasses of game during lawful hunts or culling of game by wildlife management, therefore no ethical approval was needed.

\section{Table 1}

Prevalence (\%) of Schistosoma turkestanicum in pieces of livers and faecal samples of game collected in 11 main hunting areas in Hungary

\begin{tabular}{lcccc}
\hline $\begin{array}{l}\text { Hunting areas in Hungary } \\
\text { from where the samples } \\
\text { were collected }\end{array}$ & $\begin{array}{c}\text { Investigated } \\
\text { livers of } \\
\text { red deer }\end{array}$ & $\begin{array}{c}\text { Investigated } \\
\text { livers of } \\
\text { fallow deer }\end{array}$ & $\begin{array}{c}\text { Investigated } \\
\text { droppings or } \\
\text { faeces from } \\
\text { the gut of } \\
\text { deer species }\end{array}$ & $\begin{array}{c}\text { Investigated } \\
\text { droppings of } \\
\text { wild boars }\end{array}$ \\
\hline 1. Gemenc & $50 / 176(28.4)^{*}$ & $0 / 0(0)$ & $48 / 155(30.9)$ & $0 / 100(0)$ \\
2. Karapancsa & $3 / 32(9.4)$ & $0 / 0(0)$ & $2 / 32(6.25)$ & $0 / 0(0)$ \\
3. Szekszárdi Hills & $0 / 13(0)$ & $0 / 4(0)$ & $0 / 103(0)$ & $0 / 3(0)$ \\
4. Zselic & $0 / 2(0)$ & $0 / 8(0)$ & $0 / 10(0)$ & $0 / 8(0)$ \\
5. Kis-Balaton & $0 / 0(0)$ & $0 / 0(0)$ & $0 / 21(0)$ & $0 / 5(0)$ \\
6. Bakony Mountains & $0 / 9(0)$ & $0 / 16(0)$ & $0 / 23(0)$ & $0 / 16(0)$ \\
7. Szigetköz & $0 / 17(0)$ & $0 / 0(0)$ & $0 / 48(0)$ & $0 / 0(0)$ \\
8. Pilis Mountains & $0 / 0(0)$ & $0 / 0(0)$ & $0 / 46(0)$ & $0 / 0(0)$ \\
9. Mátra Mountains & $0 / 0(0)$ & $0 / 0(0)$ & $0 / 20(0)$ & $0 / 0(0)$ \\
10. Bükk Mountains & $0 / 20(0)$ & $0 / 0(0)$ & $0 / 36(0)$ & $0 / 0(0)$ \\
11. Nyírség & $0 / 3(0)$ & $0 / 1(0)$ & $0 / 4(0)$ & $0 / 0(0)$ \\
\hline Altogether & $53 / 272(19.5)$ & $0 / 29(0)$ & $50 / 498(10.0)$ & $0 / 132(0)$ \\
\end{tabular}

*Number of positive samples/Number of samples examined (percentage of positive samples). The average of the detected prevalence of infection in 208 liver samples that came from two endemic areas of Gemenc and Karapancsa is 24.58. Samples of fallow deer and wild boars did not contain $S$. turkestanicum worms or eggs. In some cases droppings of deer usually could not be separated by species

\section{Examination of parts of internal organs}

We received mostly frozen slices of liver and segments of the small intestine. We could take samples from non-frozen offal three times. A total of 306 pieces of liver and intestine were investigated. The organs were cut into small pieces of one to two centimetres, and the worms were washed out of the veins with non-distilled tap water. The recovered $S$. turkestanicum specimens were identified by their morphology according to descriptions by Skrjabin (1951), Witenberg and Lengy (1967) and Azimov (1971). 


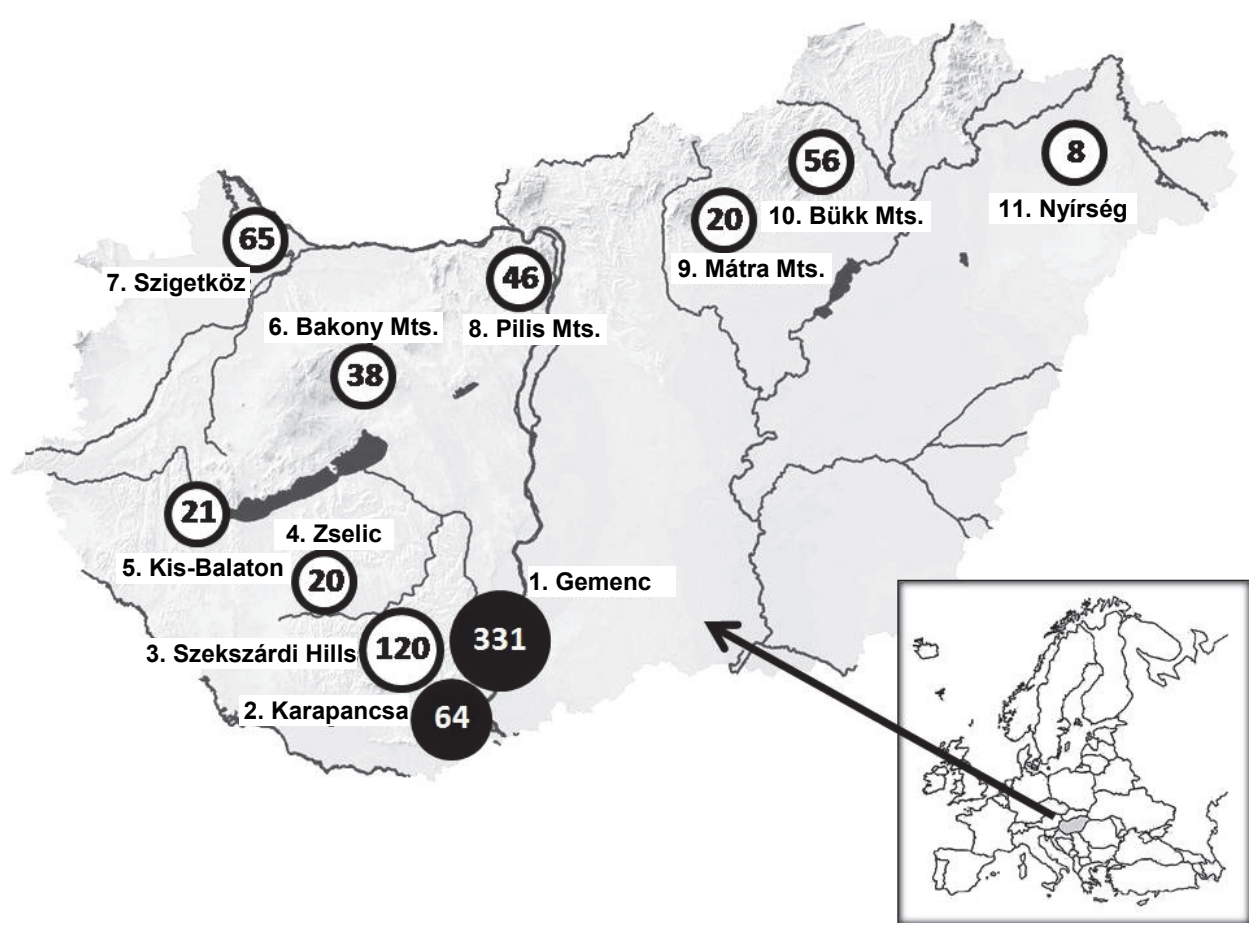

Fig. 1. Location of areas investigated for the presence of Schistosoma turkestanicum. The map shows the localities of those hunting areas in Hungary from where the examined visceral or faecal samples of deer were derived. $\bullet=$ Schistosoma-infected areas, $\mathbf{O}=$ areas where the occurrence of S. turkestanicum was investigated but has not been detected so far. The numbers and names next to the circles show areas that appear in Table 1. Numbers in the circles represent the total number of samples (organs + faecal samples) obtained from deer species (red deer and fallow deer) in the given area

Small segments of liver washed with water were placed in a household blender of 2-litre capacity and we made a suspension with tap water. Depending on the amount of suspension, 200-300 millilitres of $80 \mathrm{~g} / \mathrm{L}$ sodium hydroxide $(\mathrm{NaOH})$ was added to the suspension to achieve alkali concentration of approximately $1-2 \%$ in the mixture. The tissue suspension was then incubated at room temperature for 15 to $20 \mathrm{~h}$ followed by a second incubation, being gradually heated to $+60{ }^{\circ} \mathrm{C}$ whilst stirring and then cooled to room temperature. The solubilised tissue was filtered through a mesh screen with a mesh of $63 \mu \mathrm{m}$ aperture [230 US mesh unit] in order to filter out the tissue residues larger than the size of Schistosoma eggs. The filtered mixture was divided into conical glass bottles and was allowed to settle. The sediment was inspected by a binocular compound microscope to find the eggs of typical shape. 


\section{Collection and storage of faecal samples}

Droppings of deer were collected in forests, thickets or frequently around artificial feeding sites. The acquisition of fresh droppings is a challenge as faeces can dry quickly upon contact with the soil, can become mouldy and start to degrade and is subject to freezing during the autumn and winter months. Droppings were individually packaged in nylon bags and stored at $+4{ }^{\circ} \mathrm{C}$ for later processing. In some cases, we were able to collect faeces from the rectum of shot deer. In a similar way we collected 132 droppings of wild boars from five hunting areas for comparison.

\section{Sedimentation and staining of Schistosoma eggs in faecal samples}

Each sample collected from the ground was soaked in tap water for one day at $+4{ }^{\circ} \mathrm{C}$ to soften. In case of faecal mass from the intestine, the soaking phase was not required. The softened sample was mixed with water using a household blender. The stirring lasted from 0.5 to $1 \mathrm{~min}$, and then the suspension was diluted with 3-6 decilitres of tap water until it became very fluid. The diluted suspension was allowed to settle for at least $10 \mathrm{~min}$ in a bucket. After the 10-min incubation period the supernatant was carefully poured off to remove the plant fibres that floated on the surface or inside the water. The bucket was filled once again with tap water and the supernatant formed after sedimentation was decanted several times until the water above the sediment was clear.

The sediment was filtered through three sieves successively. A sieve with $180 \mu \mathrm{m}$ aperture [80 US mesh unit], a second sieve with $63 \mu \mathrm{m}$ aperture [230 US mesh unit] and a third sieve with $37 \mu \mathrm{m}$ aperture [400 US mesh unit] (Endecotts ${ }^{\circledR}$ Ltd., London). The pellets collected on the surface of the last sieve were retained. Using screens with mesh sizes of 63 and $37 \mu \mathrm{m}$, we removed plant particles much larger than the $S$. turkestanicum eggs and those ones which are smaller than them.

The pellet on the surface of the third screen was washed with tap water into a $200-\mathrm{ml}$ glass and allowed to settle for at least $10 \mathrm{~min}$. During this time, the solid sediment settled down to the bottom of the glass, and sharply separated from the water above it. Most of the water was discarded afterwards. According to the recommendation of Pitchford and Visser (1975) we added 2-3 $\mathrm{ml}$ of 5\% acid fuchsin and 10-15 drops of $10 \% \mathrm{HCl}$ solution to the small amount of suspension that remained in the glass. (To prepare the stain solution 50 grams of acid fuchsin was dissolved in $1000 \mathrm{ml}$ acidified water to $\mathrm{pH} 5$ with a very small amount of hydrochloric acid, which stabilised the stain mixture, helped the dye penetrate into the eggs and made their colour more intense.) Stirred with the dye and hydrochloric acid the entire mixture turns to bright red and a part of the sediment floats again on the surface.

In order to achieve the appropriate intensity of staining the debris had to stay in the acidified stain for at least $2 \mathrm{~h}$. The red suspension was then divided in- 
to $15-\mathrm{ml}$ centrifuge tubes, centrifuged at 5000-6000 relative centrifugal force (RCF) for $1 \mathrm{~min}$, and then the red stain was poured off.

\section{Flotation and microscopic examination of the eggs}

The stained pellet was mixed with successive floating density flotation solutions and centrifuged in each solution. At the top of the consecutive solutions, more and more dense particles were collected. First a saturated saline solution of $1200 \mathrm{~g} / \mathrm{L}$ was added in the bottom of the centrifuge tube to the pellet, mixed by shaking and centrifuged again in the same manner as before. A thin layer of solid particles was collected on the top of the solution but many of the particles again sank to the bottom of tube. Particles on the surface of the solution were picked up with a glass rod, smeared across the surface of a microslide and examined for eggs with a binocular compound microscope. Removal of floating objects from the surface of the solution was repeated several times.

After testing the floating debris fraction, the $1200 \mathrm{~g} / \mathrm{L}$ solution was poured off and a solution with a specific gravity of $1300 \mathrm{~g} / \mathrm{L}$ was added to the rest of the pellet in the centrifuge tube. This process was again followed by a centrifugation step, and then the examination of the floating particles was done in the same way as before. The whole process of mixing, centrifugation and examination of debris was repeated again with $1350 \mathrm{~g} / \mathrm{L}$ and $1400 \mathrm{~g} / \mathrm{L}$ solutions, respectively. In this way, the stained debris was examined successively with four solutions of different specific gravity.

\section{Preparation of flotation mixtures}

The solution with $1200 \mathrm{~g} / \mathrm{L}$ density was made of sodium chloride and water only. Subsequent solutions of higher density were made from a mixture of saline, sucrose, zinc sulphate and water, and their final densities were checked with a hydrometer. Those solutions which were prepared by mixing of the base solutions retained their specific weight for a longer time than the component solutions.

\section{Determination of the specific gravity of $\mathrm{S}$. turkestanicum eggs}

In order to determine the most appropriate density of the solution for flotation of $S$. turkestanicum eggs, a larger amount of faeces was homogenised and divided into 10 samples of 50 grams each. In this way we prepared 10 portions of fresh deer faeces and 10 portions of such old droppings that had been on the ground longer and were frozen. These 20 samples were tested in the same way as the other faecal samples. The eggs found on the surface of the consecutive flotation solutions were counted. 
The chance of finding the eggs by the investigation of a known amount of them in prepared faecal samples

Schistosoma eggs collected from the fresh faeces of deer were added to manure of cattle which was free of trematode infection and then we tried to detect them in the prepared sample. At the first test, 3, 4 or 5 eggs were added to each of the 10 different 5-gram subsamples of egg-free manure. (This low concentration of eggs was roughly equal with the amount of intact eggs in the very fresh droppings). After sieving, sedimentation and flotation with the solution of $1350 \mathrm{~g} / \mathrm{L}$ density, the eggs found were counted in each subsample.

Secondly, $200 \mathrm{~g}$ of old droppings of deer were mixed into $500 \mathrm{~g}$ of eggfree cattle manure. The very exact amount of Schistosoma eggs in the deer faeces used to make the mixture was not known, but we found that it contains in average less than one egg per gram and probably even less. Based on this, we estimate that 10 grams of the mixed deer and bovine manure we have produced could not contain more than 3 eggs, so the 'eggs per gram' (EPG) value was about 0.3 . Such a low concentration of eggs can frequently be expected in the old droppings. This artificially prepared and homogenised mass of faeces was divided into 68 individual samples of $50 \mathrm{~g}$ each, and in these samples the eggs were searched for according to the method described above.

\section{Results}

\section{Distribution and supposed prevalence of S. turkestanicum in Hungary}

Based on the examination of organs from a total of 208 deer only 53 $(25.48 \%)$ were found to be infected with $S$. turkestanicum only in the southern part of Hungary, in the Gemenc and Karapancsa forests (Table 1). No blood flukes or their eggs were found in organs from the other sites (Fig. 1). The freezing and defrosting of organs did not destroy the parasites, so the worms were often found still paired (Fig. 2). In many cases, only male $S$. turkestanicum specimens were found in the livers. Some liver fragments also had Dicrocoelium dendriticum and Fascioloides magna specimens which were particularly common in deer living along the Danube River (Majoros and Sztojkov, 1994).

Fifty per cent of the livers infected with $S$. turkestanicum contained also egg granulomas. Following the dissolution of the liver tissue by the diluted sodium hydroxide, the eggs accumulated in the sediment (Fig. 3A). The inner contents of the eggs were disintegrated and only their shells remained intact (Fig. 3B). We did not count all the eggs precisely because the total number of worms in an individual could not be determined from a small piece of liver, therefore the exact comparison of the amount of eggs and worms would not have been possible. The number of worms found in one fragment was never over 100 but usually was 5- 
10 specimens. Since the size of the pieces was on average one-tenth or onetwentieth of the livers, the maximum worm load (worm burden) of the deer was estimated to be up to a few hundred worms at most. We have found the eggs of S. turkestanicum in fewer animals than the worms themselves.

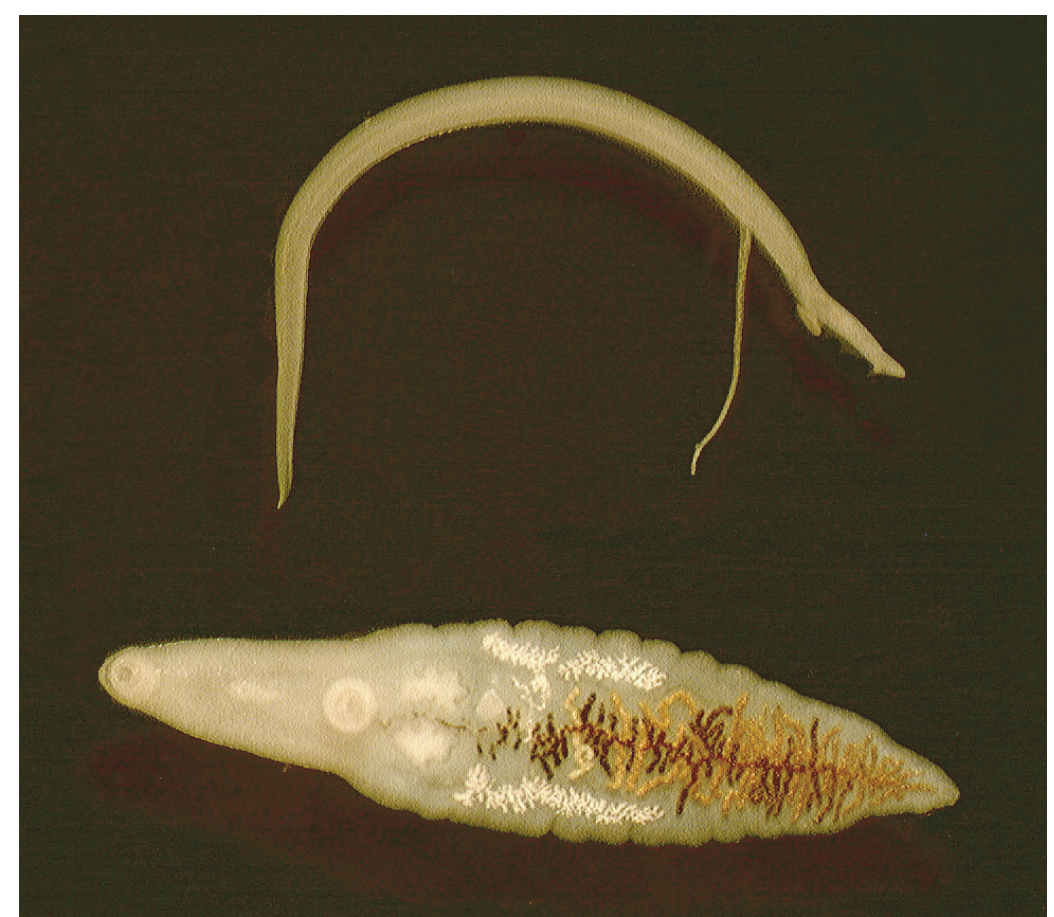

Fig. 2. A pair of Schistosoma turkestanicum (top) and a lancet fluke (Dicrocoelium lanceolatum) shown for comparison (bottom). The worms were collected from the liver of the same host individual. The length of the lancet fluke is $6 \mathrm{~mm}$

Consistent with the occurrence of parasites found in the livers, Schistoso$m a$ eggs were found only in droppings and intestinal contents of red deer in Gemenc and Karapancsa but not in other places (Table 1). In the samples collected in the other nine hunting areas no $S$. turkestanicum eggs were identified. The average prevalence of $S$. turkestanicum eggs was $26.7 \%$ in the examined deer droppings of the two infected areas, which is almost the same as the prevalence observed by the examination of viscera. It is important to note that no Schistoso$m a$ eggs were found in the 132 droppings of wild boar, but this fact does not exclude the possibility that wild boars harbour a hidden (non-patent) infection by this trematode. 


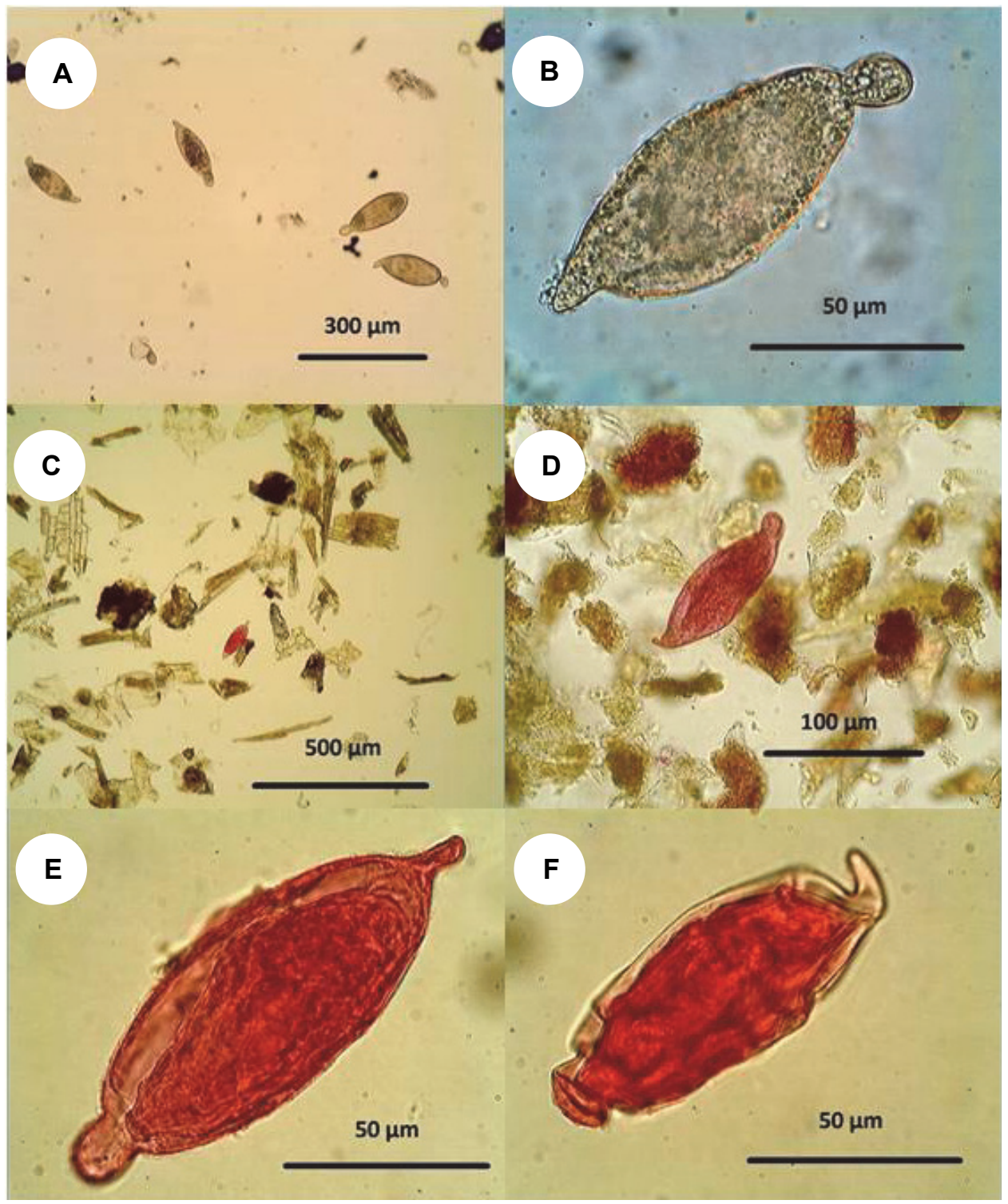

Fig. 3. The appearance of Schistosoma turkestanicum eggs during various procedures.

A: Low magnification of a group of eggs found in liquefied liver tissue. $B$ : High magnification of an unstained egg from dissolved liver tissue. Its shell is intact but its inner content is disintegrated. $C$ : A sole egg stained by acid fuchsin is well recognisable among the unstained plant debris. It is still noticeable even at low magnification. $D$ : The egg is clearly recognisable by its distinctive shape when viewed at a magnification of at least $400 \times . E$ : Within the intact egg frequently a miracidium is visible which is slightly darker than the egg capsule. $F$ : Due to its characteristic shape, the stained egg on the surface of dense solutions can be recognised even when distorted by the high osmotic pressure of the solution 


\section{The improved method for the detection of $\mathrm{S}$. turkestanicum eggs}

Most of the plant fibres were removed by decantation and filtration. The sieve with $63 \mu \mathrm{m}$ mesh did not allow the large Fascioloides eggs to contaminate the microscopic filtrate. The large number of liver fluke eggs in the faeces would have made it difficult to find Schistosoma eggs.

The fraction of finely granulated faecal debris that was retained on the sieve of $37 \mu \mathrm{m}$ mesh size consists of grains only which have a similar size to the S. turkestanicum eggs. Among the homogeneous granules of approximately the same size, the stained eggs were more prominent than they would have appeared among different-sized particles.

Schistosoma turkestanicum eggs kept the red stain during repeated mixing with the flotation solutions (Fig. 3C-F). Plant fibres are not stained or, if they are stained to pale pink sometimes, they gradually lose their mild red tones in the consecutive flotation solutions. The eggs among the grains of debris can be clearly seen even at low magnification, e.g. when applying objective lenses with $10 \times$ magnification (Fig. 3C). The application of low magnification is enough to see red eggs; however, when using a higher-magnification lens, the typical shape of the egg is more visible, making it easier to recognise (Fig. 3D).

The flotation study of 10 fresh faecal samples of the same quality and quantity showed that most of the eggs can rise to the surface in a $1350 \mathrm{~g} / \mathrm{L}$ (or higher-density) solution. If they have already been removed from the debris by solutions of lower density, the $1400 \mathrm{~g} / \mathrm{L}$ solution can raise to the surface only a small number of eggs (Table 2). There are also a small number of eggs that can be found on the surface of the $1200 \mathrm{~g} / \mathrm{L}$ or $1300 \mathrm{~g} / \mathrm{L}$ solution. In the old droppings there were far fewer eggs than in the intestinal content of hunted deer. The density of eggs in the old droppings was found to be heterogeneous and highly variable (Table 3). Based on this observation, the specific weight of intact Schistosoma eggs in the fresh faeces falls between about $1.3 \mathrm{~g} / \mathrm{cm}^{3}$ and $1.35 \mathrm{~g} / \mathrm{cm}^{3}$; however, the eggs may be much lighter or heavier in droppings that have been exposed to the weather conditions for a long time.

Known amounts of eggs in the samples of prepared cattle manure were detected with high sensitivity. From each of the 10 individual five-gram faecal samples artificially inoculated with $S$. turkestanicum eggs the majority of the eggs were recovered (Table 4). All samples were found to be positive by test method described above; therefore, this test could detect the real prevalence of the parasite in samples using the novel approach. A total of 44 eggs were added to the 10 samples of faeces. Twenty-four of the eggs, namely $54.5 \%$, were recovered. The average number of eggs in each gram of sample was $0.88(E P G=$ 0.88). This result shows that Schistosoma eggs can be found by the method employed by us even if every gram of faeces contains only one egg or less on the average. 

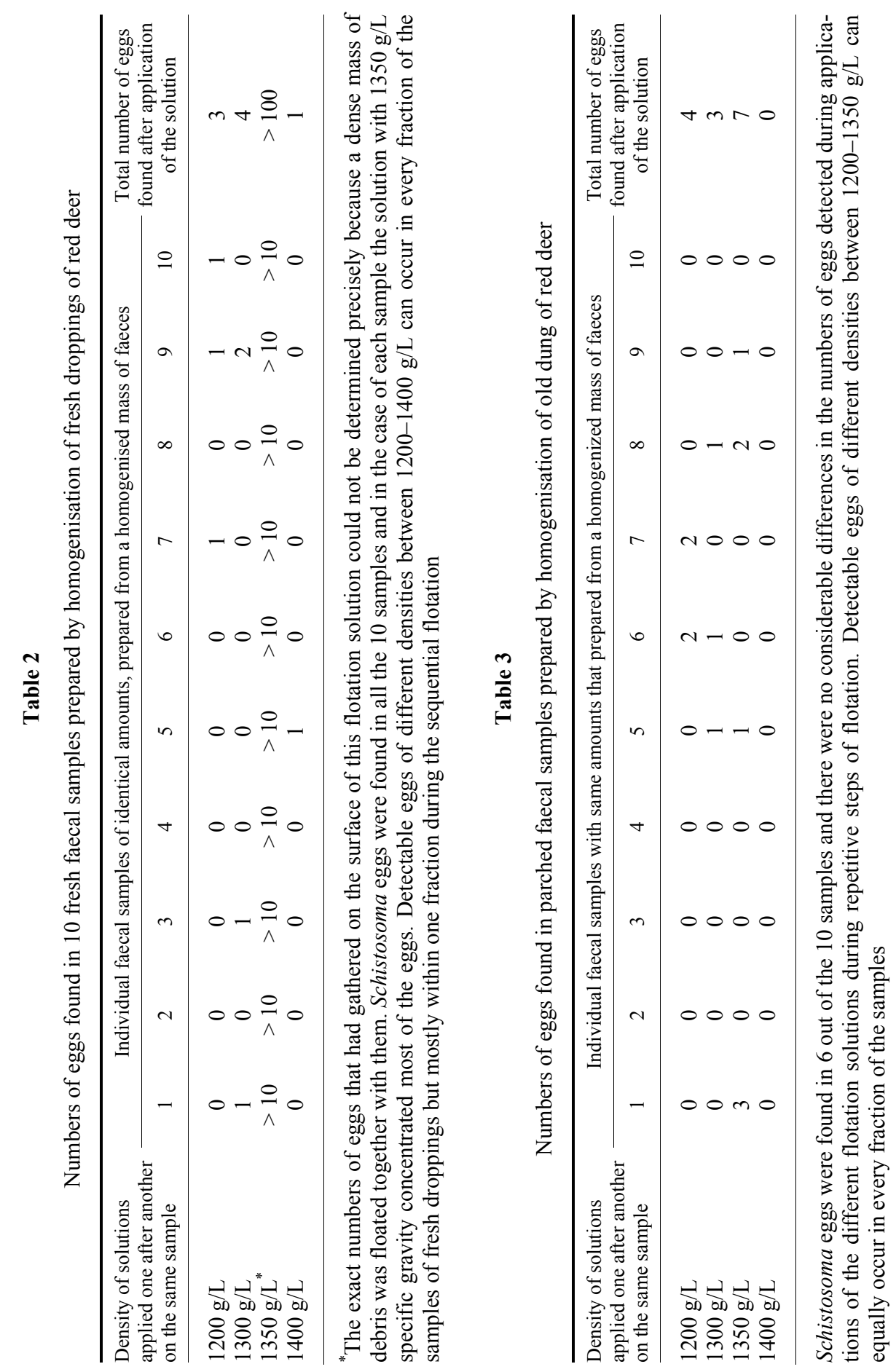
Table 4

Total number of Schistosoma eggs added to 10 equalised samples of negative (egg-free) cattle faeces and the number of eggs recovered

\begin{tabular}{ccc}
\hline Weight of faecal sample in grams & Number of eggs added & Number of eggs recovered \\
\hline 5 & 4 & 1 \\
5 & 4 & 2 \\
5 & 5 & 2 \\
5 & 3 & 1 \\
5 & 5 & 5 \\
5 & 5 & 4 \\
5 & 5 & 3 \\
5 & 3 & 1 \\
5 & 5 & 2 \\
5 & 5 & Total: 24 \\
Total: $50 \mathrm{~g}$ & Total: 44 & Average: 2.4 eggs/sample \\
\hline
\end{tabular}

The detected prevalence of positive samples is $100 \%$. The percentage of all recovered eggs is $54.54 \%$

Using another approach we diluted and homogenised the dung of deer with egg-free cattle manure in order to imitate the very low concentration of recognisable Schistosoma eggs at the same density at which they are frequently found in droppings on the ground. In the mass of mixture the amount of eggs roughly corresponded to that usually found in old droppings drying on the ground. We divided the mixture into 68 individual subsamples that contained probably an equal quantity of eggs as a result of the homogenisation. The samples contained no more than 0.3 eggs per gram, i.e. 15 eggs per 50 grams. We recovered eggs from 14 samples (Table 5). It seems that by the combined detection method used by us it is possible to recognise the eggs in at least $25 \%$ of very old droppings.

\section{Discussion}

Based on molecular studies on the occurrence of S. turkestanicum in Central Europe, the parasite is most likely to be part of the long-established native fauna of Hungary. It is probably not recently introduced by humans (Lawton and Majoros, 2013), and most likely will infect not only red deer of the Gemenc forests but also other hosts across Hungary. It would be possible to find these trematodes in wild animals living in different parts of the country on the basis of a large number of samples. With this focus, we set ourselves the goal of developing a method for diagnosing $S$. turkestanicum infection, which allows a large number of samples to be examined throughout the year. Investigations should 
preferably be carried out in such a way that they are as independent as possible from hunting activity. There are two reasons for this. Firstly, during the hunting ban from January to September direct examination of deer's body is not possible. Secondly, during the winter hunting season it is much easier to collect droppings in artificial feeding places than to obtain organs from eviscerated deer.

\section{Table 5}

Detected prevalence and numbers of eggs found in 68 faecal samples prepared by homogenisation of several old droppings of red deer, diluted with egg-free cattle manure and repeatedly investigated in solutions of different specific gravity ranging from 1200 to $1400 \mathrm{~g} / \mathrm{L}$

\begin{tabular}{cc}
\hline Number of samples examined & Number of eggs recovered \\
\hline 54 & 0 \\
11 & 1 \\
2 & 2 \\
1 & 3 \\
\hline
\end{tabular}

Each gram of homogenised droppings contained certainly less than one $S$. turkestanicum egg. Subsamples of the homogenised mass of dung weighed $50 \mathrm{~g}$ and most probably might have contained 5-20 eggs. Altogether 14 samples (i.e. $\sim 20.6 \%$ of the samples) were found to be positive by the repeated flotation (mean: 0.088; standard deviation: 0.06; coefficient of variation: 0.7 )

Our results show that, in the areas where Schistosoma infection in deer was confirmed by the examination of the visceral organs, S. turkestanicum eggs could also be detected from the droppings, even if they were present only in small quantities. By combining the advantages of the applied methods, it is possible to screen a large number of samples to detect the presence of Schistosoma in large mammals of a given area regardless of hunting activity.

The investigated number of organs (and faecal samples) was not related either to the size of the deer population in the area or to the number of animals shot by hunters. On the basis of the examination of the organs, it was only possible to find the presence of Schistosoma in two areas of South Hungary, Gemenc and Karapancsa (Fig. 1). These areas are close to the flood plains of Serbia and Croatia, so it is likely that the parasite is also present in these latter countries.

The detected prevalence of worms in deer of Gemenc was $28.4 \%$ and, based on the investigation of eggs in droppings, the prevalence of infection was even a little higher (30.9\%) in the same population (Table 1). Taking into consideration two important facts, i.e. that we could investigate only a small piece of organs from every animal and the infected individuals did not always shed eggs with their faeces, the number of infected animals can certainly be supposed to be higher than what we found. Therefore, it can be assumed that the true prevalence of $S$. turkestanicum in deer living on the southern floodplains of the river Danube 
is between 20 and $50 \%$, but the average number of worms in animals, which is roughly equal to the intensity of infection, is likely to be low.

Schistosoma turkestanicum eggs can be detected reliably by solubilisation of the liver tissue with sodium hydroxide. In each liver in which we found at least 10-20 worms we could detect at least some eggs, but we could not find any eggs in slices with only 1 to 5 worms. The dissolution of liver tissue with lye has similar effects as artificial digestion (Smithers, 1960) which was also used to detect eggs of Schistosoma bovis in the liver (Kassuku et al., 1985) and is a proven method for detecting Schistosoma eggs also in faeces (Vohra and Agrawal, 2006; Cherian and D'Souza, 2009). After treatment with sodium hydroxide, the shells of the eggs remained intact and therefore the eggs remained recognisable despite their internal dissolution (Fig. 2A-B). The Schistosoma eggs are usually embedded in a coat of epitheloid cells and fibrous stroma (Yamagiwa, 1931; De Bont and Vercruysse, 1998), which must be removed with an alkali (or enzyme) so that the egg can be recognised. Solubilisation of the mucus or tissues even by hot $\mathrm{KOH}$ could be effectively applied for detecting eggs of other schistosomes too (Muraleedharan et al., 1976; Kassuku et al., 1985).

Unfortunately, it is difficult to detect the eggs of blood flukes in droppings collected from the ground for a number of reasons. In our preliminary studies, it was found that there are very few eggs in the intestinal content of those deer which have more than 100 pairs of $S$. turkestanicum worms in the liver (unpublished observation). This is not surprising because in many cases very few eggs were found in cattle in the case of bovine schistosome infection as well (Makundi et al., 1998). It was found that the density of eggs in the faeces is not closely related to the amount of worms present in the animals (De Bont and Vercruysse, 1998). Older ruminants infected with a higher number of worms shed far less eggs than do younger animals which carry a lower amount of worms, and even the shedding of eggs is seasonal (Agrawal, 2012). Compared to the blood fluke infection of domestic ruminants (i.e. cattle) in tropical countries, it seems that Hungarian red deer, for unknown reasons, usually have even lower worm burdens, and therefore very few Schistosoma eggs can be expected to be present in their faeces.

In the current study there were only a few eggs in droppings collected from the ground. In most cases, only a single egg was found in lots of homogenised and split faecal samples weighing 50 grams (Table 5) or 100 grams in other studies conducted by us. In the old droppings the amount of eggs only occasionally exceeded 1 EPG. This is such a low egg density that cannot be detected by sedimentation or filtration methods alone. By methods that only use filtration and sedimentation to concentrate the eggs, egg counts lower than 10 to 20 eggs per gram were not detected (Pitchford and Visser, 1975). A detection method for the eggs, which applied flotation after filtration and sedimentation, was more sensitive (Teuscher, 1965); therefore, we combined the three methods for detecting Schistosoma eggs. 
None of the eggs in droppings collected from ground were intact, and some of them were broken and distorted. During the procedures used to concentrate the eggs, these damaged eggs behave differently to intact eggs, because their specific weight, shape and constituents change during their stay in the decomposing faeces. Because of decomposition, we have less chance to detect eggs in droppings than to find them directly in the intestinal contents. Since the larvae in the eggs are soon destroyed in the manure, we cannot efficiently detect the presence of schistosome eggs if we wait for the miracidia to hatch, although this procedure has been used for a long time to inspect human stool or animal excreta (Terner, 1962; Goff and Ronald, 1980; Malek, 1980; Makundi et al., 1998; Jurberg et al., 2008; Zhu et al., 2014).

Therefore, the eggs could not be detected in deer faeces by methods used for examining the parasite content of human stool (Ritchie, 1948; Chaia et al., 1968; Katz et al., 1970; Ebrahim et al., 1997) in case of such low egg concentrations. For the same reason, we have not found the various methods previously recommended for the detection of schistosome eggs in animal faeces sensitive enough to detect eggs.

The principle of the sequential flotation we describe is based on the following considerations. We cannot always know in advance the actual density (i.e. specific gravity) of the parasite we are looking for, but it is very likely that most of them fall into a density range typical of them. Therefore, if we examine the different density fractions of the sample one after the other, we will surely find one in which the parasite occurs at a much higher frequency than in the rest. In this way one can increase the probability of discovering the eggs in a sample.

As faecal samples contain so many particles of different density, it is impossible that only the eggs are aggregated on the surface of the salt solutions. Of course, if only the densest solution is used for the flotation, all the eggs of worms will raise to the surface, but in this case there is so much debris rising with them to the surface that the eggs cannot be found among them. Therefore, it is advisable to use at least four solutions of different density $(1200 \mathrm{~g} / \mathrm{L}, 1300 \mathrm{~g} / \mathrm{L}, 1350 \mathrm{~g} / \mathrm{L}$ and $1400 \mathrm{~g} / \mathrm{L}$ ) to test the same sample, and thus to divide the floating debris into four fractions. In doing so, at least one fraction is more likely to contain the eggs than the others. During our investigations, the freshly shed, intact eggs (Fig. 3E) were concentrated at the top of the $1350 \mathrm{~g} / \mathrm{L}$ solution, but dead eggs in the old dung appeared at similar frequencies on the surface of each flotation solution. It is therefore recommended that each of the fractions of faeces assembled on the surface of different density solutions be individually examined.

Rather than the chemical composition of the solutions used for flotation, only their density is relevant for separation of the eggs. However, in the method we propose, it should be ensured that the flotation solution should in no way be alkaline but rather slightly acidic, because a hydrogen ion concentration above $\mathrm{pH} 7$ prevents the acid fuchsin from staining. In the current study we used com- 
mon salt $(\mathrm{NaCl})$, sucrose, zinc sulphate of technical grade, and distilled water. There were two important reasons why we did not use the pure solutions of these chemicals but their mixtures. First, the solution of the mixed materials is more slowly crystallised than the pure, saturated solution of their components, so the formation of crystals in the drop of mixture started slowly after being placed on the microscope slide. Secondly, the advantage of mixtures of substances that can be mixed with one another without chemical reaction is that the suspended debris can easily be transferred from one solution to the other without precipitation during mixing. The wetting properties of the solutions are also the same, and the grains in them do not adhere to each other. Therefore, the particles of the faecal matter suspended within them are well separated from each other. A mild shrinkage was observed on the eggs which floated on the consecutive solutions with growing density (Fig. 3F). Shrinkage was not so disturbing that it would have made impossible their recognition.

The consecutive flotations that followed the aqueous decanting, filtration and staining of the faeces are considered to be suitable for the large-volume coprology test of old droppings collected from the ground.

In conclusion: Far from its original Asian distribution the S. turkestanicum blood fluke, being a parasite of red deer, has a natural habitat in the southern part of Hungary but it may occur also elsewhere in Europe. A consequence of the low worm burden in deer is that this host sheds few eggs in its faeces, therefore it is hard to find them in the droppings; although these kinds of samples are suitable for detecting the presence of the parasite in red deer populations. An effective method is needed to concentrate the eggs of schistosomes in droppings to reveal the fact of infection and to apply the eggs for other investigations, e.g. molecular works. Sequential flotation seems to be useful for detecting even very low amounts of eggs in faecal samples. The recognition of eggs can be facilitated by counter-staining with acid fuchsin.

\section{Acknowledgements}

Thanks to the professional hunters of the Gemenc Forest and Game Co. Ltd. and many unknown hunters who provided samples for the tests. Several enthusiastic veterinary students have contributed to increasing the amount of test substances. The authors are grateful to Dr Scott P. Lawton of Kingston University London and Zoltán Petrovics for their remarks and for improving the English of the manuscript. AJ was supported by her PhD scholarship. This research was supported by the 17896-4/2018/FEKUTSTRAT grant of the Hungarian Ministry of Human Capacities. 


\section{References}

Agrawal, M. (2012): Schistosomes and schistosomiasis in South Asia. Springer (India) Pvt. Ltd., New Delhi. pp. 101-112.

Agrawal, M. C. and Alwar, V. S. (1992): Nasal schistosomiasis: A review. Helminthol. Abstr. 61, $373-384$.

Aldhoun, J. and Littlewood, D. (2012): Orientobilharzia Dutt \& Srivastava, 1955 (Trematoda: Schistosomatidae), a junior synonym of Schistosoma Weinland 1858. Syst. Parasitol. 82, 81-88.

Arfaa, F., Sabbaghian, H. and Ale-Dawood, H. (1995): Studies on Ornithobilharzia turkestanicum (Skrjabin, 1913). Ann. Parasitol. Hum. Com. 40, 45-50.

Azimov, D. A. (1971): Ontogeny of Orientobilharzia turkestanica (Skrjabin, 1913) trematode (in Russian). Uzbekskiy Biologitseskiy J. 2, 49-52.

Brant, S., Pomajbíková, K., Modry, D., Petrželková, K., Todd, A. and Loker, E. (2013): Molecular phylogenetics of the elephant schistosome Bivitellobilharzia loxodontae (Trematoda: Schistosomatidae) from the Central African Republic. J. Helminthol. 87, 102-107.

Červená, B., Brant, S., Fairet, E., Shirley, M., Petrželková, K. and Modrý, D. (2016): Schistosoma mansoni in Gabon: emerging or ignored? Am. J. Trop. Med. Hyg. 95, 849-851.

Chaia, G., Chaia, A. B. Q., MacAullife, J., Katz, N. and Gasper, D. (1968): Coprological diagnosis of schistosomiasis. II. Comparative study of quantitative methods. Rev. Inst. Med. Trop. Sao Paulo 10, 349-359.

Cherian, S. and D'Souza, P. E. (2009): Coprological diagnosis of ovine schistosomosis by different laboratory techniques. Vet. World 2, 271-273.

De Bont, J. and Vercruysse, J. (1998): Schistosomiasis in cattle. Adv. Parasitol. 41, 285-364.

Ebrahim, A., El-Morshedy, H., Omer, E., El-Daly, S. and Barakat, R. (1997): Evaluation of the Kato-Katz thick smear and formol ether sedimentation techniques for quantitative diagnosis of Schistosoma mansoni infection. Am. J. Trop. Med. Hyg. 57, 706-708.

Farahnak, A. and Essalat, M. (2003): A study on cercarial dermatitis in Khoozestan Province, Southwestern Iran. BMC Public Health 3, 35-38.

Goff, W. and Ronald, N. (1980): Miracidia hatching technique for diagnosis of canine schistosomiasis. J. Am. Vet. Med. Assoc. 11, 699-700.

Juhász, A., Dán, Á., Dénes, B., Kucsera, I., Danka, J. and Majoros, G. (2016): A rare zoonosis in Hungary: cercarial dermatitis caused by the Schistosoma turkestanicum blood fluke [in Hungarian]. Orv. Hetil. 157, 1579-1586.

Jurberg, A., Oliveira, A., Lenzi, H. and Coelho, P. (2008): A new miracidia hatching device for diagnosing schistosomiasis. Mem. Inst. Oswaldo Cruz 103, 112-114.

Kassai, T., Cordero del Campillo, M., Euzeby, J., Gaafar, S., Hiepe, Th. and Himonas, C. A. (1988): Standardized nomenclature of animal parasitic diseases (SNOAPAD). Vet. Parasitol. 29, 299-326.

Kassuku, A. A., Makundi, A. E. and Knudsen, J. (1985): Comparative methods used in diagnosis in ruminant schistosomiasis. Tanzania Vet. Bull. 7, 1-8.

Katz, N., Coelho, P. M. Z. and Pellegrino, J. (1970): Evaluation of Kato's quantitative method through through recovery of Schistosoma mansoni eggs added to human feces. J. Parasitol. 56, 1032-1033.

Kolarova, L. (2007): Schistosomes causing cercarial dermatitis: a mini-review of current trends in systematics and of host specificity and pathogenicity Folia Parasitol. 54, 81-87.

Lawton, S. and Majoros, G. (2013): A foreign invader or a reclusive native? DNA bar coding reveals a distinct European lineage of the zoonotic parasite Schistosoma turkestanicum [syn. Orientobilharzia turkestanicum (Dutt and Srivastava, 1955)]. Infect. Genet. Evol. 14, 186-193.

Lien, C. A., Pai, K. M., Su, L., Liu, C. M., Chen, M. S. and Liu, C. (1975): A survey of the aetiological agent of rice field dermatitis in Chengnan People's Commune, Hailung Hsien, Kirin 
Province, with a preliminary observation of the life history of Orientobilharzia turkestanica var. tuberculata [in Chinese, with English summary]. Acta Zool. Sinica 21, 183-189.

Liu, C., Chao, S. and Niu, S. (1976): A survey of the aetiological agent of rice-field dermatitis with studies on the life-cycle of Orientobilharzia turkestanica var. tuberculata in Jilin Province [in Chinese, with English summary]. Acta Zool. Sinica 22, 279-287.

Liu, G. H., Xu, M. J., Chang, Q. C., Gao, J. F., Wang, C. R. and Zhu, X. Q. (2016): De novo transcriptomic analysis of the female and male adults of the blood fluke Schistosoma turkestanicum. Parasit. Vectors 11, 143.

Majoros, G., Dán, Á. and Erdélyi, K. (2010): A natural focus of the blood fluke Orientobilharzia turkestanica (Skrjabin, 1913) (Trematoda: Schistosomatidae) in red deer (Cervus elaphus) in Hungary. Vet. Parasitol. 170, 218-223.

Majoros, G. and Sztojkov, V. (1994): Appearence of the large American liver fluke Fascioloides magna (Bassi, 1875) (Trematoda: Fasciolata) in Hungary. Parasit. Hung. 27, 27-38.

Makundi, A. E., Kassuku, A. A., Maselle, R. M. and Boa, E. M. (1998): Distribution, prevalence and intensity of Schistosoma bovis infection in cattle in Iringa district. Tanzania Vet. Parasitol. 75, 59-69.

Malek, E. A. (1980): Snail-Transmitted Parasitic Diseases. Volume 1. CRC Press, Boca Raton, Florida. pp. 179-307.

Maleki, M., Khodokaram, A., Oryan, A., Aslani, M., Housseinzadeh, S. and Sadjjadi, S. (1994): Pathological findings in ornithobilharziasis in the herds of sheep and goat of Assyrians in Fars Province Iran. Res. Reconstruct. 24, 143.

Manson-Bahr, P. E. C. and Bell, D. R. (1987): Manson's Tropical Diseases. Baillière Tindall, London. pp. 698-725.

Massoud, J. (1971): The pathology of Ornithobilharzia turkestanicum and Schistosoma bovis in cattle, sheep and goats in Iran. J. Trans. R. Soc. Trop. Med. Hyg. 65, 431.

Massoud, J. (1973): Studies on the schistosomes of domestic animals in Iran: Observations on $\mathrm{Or}$ nithobilharzia turkestanicum (Skrjabin, 1913) in Khuzestan. J. Helminthol. 47, 165-180.

Muraleedharan, K., Kumar, S. P. and Hedge, K. S. (1976): An efficient egg counting technique for nasal schistosomiasis. Indian Vet. J. 53, 143-146.

Pitchford, R. (1976): Preliminary observations on the distribution, definitive hosts and possible relation with other schistosomes of Schistosoma margrebowiei Le Roux, 1933 and Schistosoma leiperi Le Roux, 1955. J. Helminthol. 50, 111-123.

Pitchford, R. and Visser, P. (1975): A simple and rapid technique for quantitative estimation of helminth eggs in human and animal excreta with special reference to Schistosoma sp. Trans. R. Soc. Trop. Med. Hyg. 69, 318-322.

Pitchford, R. and Visser, P. (1981): Schistosoma Weinland, 1858 from Hippopotamus amphibius Linnaeus, 1758 in the Kruger National Park. Onderstepoort J. Vet. Res. 48, 4, 181-184.

Ritchie, L. (1948): An ether sedimentation technique for routine stool examinations. Bull. U. S. Army Med. Dep. 8, 326.

Rudge, J., Carabin, H., Balolong, E., Tallo, V., Shrivastava, J., Lu, D., Basáñez, M. G., Olveda, R., McGarvey, S. T. and Webster, J. P. (2008): Population genetics of Schistosoma japonicum within the Philippines suggest high levels of transmission between humans and dogs. PLoS Negl. Trop. Dis. 2, 340.

Sahba, G. and Malek, E. (1979): Dermatitis caused by cercariae of Ornithobilharzia turkestanicum in the Caspian Sea area of Iran. Am. J. Trop. Med. Hyg. 28, 912-913.

Skrjabin, K. I. (1951): Trematodes of Animals and Man [in Russian]. Izdatelstvo Akademii Nauk SSSR, Moskva 5, 320-330.

Smithers, S. R. (1960): The isolation of viable schistosome eggs by a digestion technique. Trans. R. Soc. Trop. Med. Hyg. 54, 68-70.

Terner, H. (1962): Hatching method for Schistosoma mansoni. Complementary technic for the finding of schistosomiasis. N. Engl. J. Med. 267, 245-246. 
Teuscher, E. (1965): A new single method of examining faeces for the diagnosis of helminth diseases of ruminants. Zbl. Vet-med. B 12, 241-249.

Utzinger, J., Raso, G., Brooker, S., De Savigny, D., Tanner, M., Øornbjerg, N., Singer, B. H. and N'Goran, E. K. (2009): Schistosomiasis and neglected tropical diseases: towards integrated and sustainable control and a word of caution. Parasitology 136, 1859-1874.

Vohra, S. and Agrawal, M. C. (2006): Prevalence of caprine schistosomiasis as determined by different coprological methods. Indian Vet. J. 83, 1160-1163.

Wang, C., Li, L., Ni, H. B., Zhai, Y. Q., Chen, A. H., Chen, J. and Zhu, X. Q. (2009): Orientobilharzia turkestanicum is a member of Schistosoma genus based on phylogenetic analysis using ribosomal DNA sequences. Exp. Parasitol. 121, 193-197.

Witenberg, G. and Lengy, J. (1966): A case of natural infection of field rats with Ornithobilharzia turkestanica. Refuah Vet. 23, 67-74.

Yamagiwa, S. (1931): A study of lesions caused by the invasion of Schistosoma turkestanicum in cattle. J. Jap. Soc. Vet. Sci. 2, 131-132.

Zakhryalov, Y. N. (1978): The character and components of a natural focus of Orientobilharzia turkestanicum in the Far-East [in Russian]. Voprosy Prirodnoj Ochagovosti Boleznei 9, 76-81.

Zhu, H. Q., Xu, J., Zhu, R., Cao, C. L., Bao, Z. P., Yu, Q., Zhang, L. J., Xu, X. L., Feng, Z. and Guo, J. G. (2014): Comparison of the miracidium hatching test and modified Kato-Katz method for detecting Schistosoma japonicum in low prevalence areas of China. Southeast Asian J. Trop. Med. Public Health 45, 20-25. 